\title{
TITLE:
}

\section{Hydrogen traps in ion-irradiated F82H steel observed by NRA}

\section{$\operatorname{AUTHOR}(\mathrm{S}):$}

Takagi, Ikuji; Komura, Tetsuya; Akiyoshi, Masafumi; Moritani, Kimikazu; Sasaki, Takayuki; Moriyama, Hirotake

\section{CITATION:}

Takagi, Ikuji ... [et al]. Hydrogen traps in ion-irradiated F82 H steel observed by NRA. Journal of Nuclear Materials 2013, 442(1-3, Supplement 1): S33-\$37

\section{ISSUE DATE:}

2013-11

URL:

http://hdl.handle.net/2433/179384

\section{RIGHT:}

C 2013 Elsevier B.V.; 許諾条件により本文は2013-11-11に公開.; This is not the published version. Please cite only the published version.; この 論文は出版社版でありません。引用の際には出版社版をご確認ご利用 ください。 


\title{
Hydrogen traps in ion-irradiated F82H steel observed by NRA
}

Ikuji Takagi ${ }^{\mathrm{a}}$, Tetsuya Komura ${ }^{\mathrm{a}}$, Masafumi Akiyoshi ${ }^{\mathrm{a}}$, Kimikazu Moritani ${ }^{\mathrm{a}}$, Takayuki Sasaki ${ }^{\mathrm{a}}$, Hirotake Moriyama ${ }^{b}$

a Department of Nuclear Engineering, Kyoto University, Kyoto Daigaku-Katsura, Kyoto 615-8540, Japan.

${ }^{\mathrm{b}}$ Research Reactor Institute, Kyoto University, Kumatori-cho, Osaka 590-0494, Japan.

\begin{abstract}
Characteristics of irradiation-induced trapping of hydrogen were investigated for quantitative evaluation of tritium retention in $\mathrm{F} 82 \mathrm{H}$ steel. Before and after irradiation of 0.8 $\mathrm{MeV}{ }^{4} \mathrm{He}$ or $0.3-\mathrm{MeV} \mathrm{H}$ ions, deuterium depth profiles near the surface of a disk sample were observed by nuclear reaction analysis under continuous exposure of deuterium plasma. One type of trap, with a trapping energy of $0.66 \mathrm{eV}$, was observed after each irradiation. The ratio of trap production rate to atomic displacement was 0.0046 and 0.0014 for $\mathrm{He}$ and $\mathrm{H}$ irradiation, respectively. Annihilation occurred around $600 \mathrm{~K}$ for $\mathrm{H}$ irradiation but was not observed even at $691 \mathrm{~K}$ for $\mathrm{He}$ irradiation. Traps are likely to be interstitial-like sites associated with dislocation loops. This study also indicates that helium plays a role in inhibiting trap annihilation. In addition, the deuterium diffusion coefficient in non-irradiated F82H was determined by a time-lag permeation experiment.
\end{abstract}

Corresponding author. takagi@nucleng.kyoto-u.ac.jp (I. Takagi) 


\section{Introduction}

$\mathrm{F} 82 \mathrm{H}$ ferritic/martensitic steel is a candidate material for structural components of a fusion reactor due to its low-activation property [1]. When the components are heavily irradiated by fast neutrons, irradiation damage and irradiation-induced defects are produced that can act as hydrogen traps and increase tritium retention. Quantitative evaluation of tritium retention requires an understanding of the characteristics of the traps (e.g., trapping energy and trap density). However, limited data are available regarding hydrogen trapping in irradiated low-activation steel.

Forcey et al. [2] observed transient deuterium permeation through MANET II martensitic steel and derived the trapping energy $(0.62 \mathrm{eV})$ and the diffusion coefficient. Serra et al. [3] used a similar permeation technique to obtain the trapping energies of $0.58 \mathrm{eV}$ for $\mathrm{F} 82 \mathrm{H}$ and $0.45 \mathrm{eV}$ for BATMAN, respectively. These studies suggest intrinsic traps for hydrogen isotopes in ferritic/martensitic steels. When steel is irradiated, irradiation-induced traps are added to the intrinsic traps and analysis of permeation behavior becomes more complex.

The present work investigates the characteristics of hydrogen traps in $\mathrm{F} 82 \mathrm{H}$ steel using an in-situ observation technique [4]. This technique allows for the observation of deuterium concentration in a sample under steady-state permeation conditions and, therefore, for estimating the amount of deuterium in irradiation-induced traps (as will be shown later).

\section{Experiments}

Two experiments on deuterium trapping were conducted. One was a transient permeation experiment to estimate diffusion coefficient and observe the intrinsic traps. The other was an in situ observation of deuterium depth profiles before/after ion bombardment to characterize irradiation-induced traps. 


\subsection{Transient permeation}

A disk sample with thickness of $2.0 \mathrm{~mm}$ and diameter of $21 \mathrm{~mm}$ was cut from a $\mathrm{F} 82 \mathrm{H}$ block and mechanically polished with $0.3-\mu \mathrm{m}$ alumina. A general composition of $\mathrm{F} 82 \mathrm{H}$ is 0.1 $\mathrm{C}, 8 \mathrm{Cr}, 2 \mathrm{~W}, 0.2 \mathrm{~V}$, and $0.04 \mathrm{Ta}$ in $\%$ and $\mathrm{Fe}[5]$.

The experimental setup has been detailed elsewhere [6] and only briefly described here. The sample was set between two vacuum chambers and one side of the sample was exposed to deuterium radio-frequency (RF) plasma. The RF power was $20 \mathrm{~W}$ and discharge pressure was $1 \mathrm{~Pa}$. Because the energy of deuterium particles incident on the sample was very low, typically $1 \mathrm{eV}$ [7], there were no effects of defect formation or temperature change. A mechanical shutter with one large and several small holes was located between the plasma and the sample. As the position of the shutter was switched between the large hole and the small holes, the incident deuterium flux was changed instantaneously. A quadrupole mass analyzer was used to observe the transient behavior of deuterium permeation through the sample between 408 and $667 \mathrm{~K}$.

The transient permeation behavior was analyzed by the time-lag method [8]. In this experiment, the incident flux never becomes zero and the apparent diffusion coefficient $\left(D_{a}\right)$ is related to lag-time $(\tau)$ by [9].

$$
\tau=\frac{L^{2}}{6 D_{a}}\left(1-\frac{J_{i}}{J_{f}}\right)
$$

where $J_{i}$ and $J_{f}$ are the permeation flux at the steady state before and after the shutter is switched, respectively, and $L$ the sample thickness. The lag time $(\tau)$ is an intercept of the asymptotic line, which is the time-integrated function of the permeation flux.

\subsection{In-situ observation of $D$ trapping}


Sample material, size, and polishing were the same as described above, as was the experimental setup except that the shutter was removed and the chamber connected to a beam duct of the 4MV van de Graaff accelerator of Kyoto University. Details of the experimental setup are explained elsewhere [10].

Deuterium depth profiles near the plasma-exposed surface of the sample were measured by nuclear reaction analysis (NRA) using the reaction $\mathrm{D}\left({ }^{3} \mathrm{He}, \mathrm{p}\right){ }^{4} \mathrm{He} . \mathrm{A}^{3} \mathrm{He}^{+}$beam with 1.7 $\mathrm{MeV}$ energy was injected in the sample at $45^{\circ}$ and produced protons emitted at $174.3^{\circ}$ were detected by a solid-state detector. The proton energy spectrum was converted to a deuterium depth profile from surface to $1.5 \mu \mathrm{m}$-depth. The ion flux was kept below $1 \times 10^{16} \mathrm{~m}^{-2} \mathrm{~s}^{-1}$ to avoid temperature increases in the sample.

To introduce damage, the sample was irradiated with $0.8 \mathrm{MeV}^{4} \mathrm{He}$ ions or $0.9 \mathrm{MeV} \mathrm{H}_{3}$ ions at $45^{\circ}$. Typical ion flux was $3.5 \times 10^{16}$ and $2 \times 10^{16} \mathrm{~m}^{-2} \mathrm{~s}^{-1}$ for ${ }^{4} \mathrm{He}$ and $\mathrm{H}_{3}$, respectively. A total particle dose was $1.5 \times 10^{21}$ and $1.0 \times 10^{22} \mathrm{~m}^{-2}$ for ${ }^{4} \mathrm{He}$ and $\mathrm{H}$, respectively. Before and after the irradiation, NRA was conducted to observe changes in the deuterium concentration. It should be noted that one side of the sample was continuously exposed to plasma and the deuterium concentration was observed under steady state permeation conditions.

\section{Results and discussion}

\subsection{Deuterium diffusion}

Fig. 1 shows typical permeation curves of deuterium observed at $626 \mathrm{~K}$ after the shutter was switched to the large hole (increase) and to the small holes (decrease). Permeation curves calculated with $D_{a}$ [9], which is derived by the time-lag method, agree with the experimental data as shown in Fig.1. At other temperatures between 408 and $667 \mathrm{~K}$, all the experimental data are well reproduced by $D_{a}$. This indicates that the permeation is limited by diffusion. 
As shown in Fig. 2, $D_{a}$ data obtained in the above experiment lie on a straight line at higher temperatures but deviate below $550 \mathrm{~K}$ due to a delay from the intrinsic traps. Assuming a local equilibrium exists between deuterium atoms in solution sites and in traps and that the trap occupation is small, $D_{a}$ can be related to the diffusion coefficient $D$ by $[2$, 11],

$$
D_{a}=D\left[1+\left(C_{0} / h N\right) \exp \left(E_{t} / k T\right)\right]^{-1}
$$

where $C_{0}$ and $h N$ are the density of the trap and the solution site, respectively, $E_{t}$ is the trapping energy, $k$ is the Boltzmann constant, $T$ is the temperature, $h$ is the number of solution sites per host atom, and $N$ is the host atomic density. In general, $h=6$ for martensitic steel [2]. As $D_{a}$ approaches $D$ at higher temperatures, $D$ is estimated from the data between 556 and $667 \mathrm{~K}$, that is,

$$
D=3.6 \times 10^{-8} \exp (-0.076[\mathrm{eV}] / k T) \quad \mathrm{m}^{2} \mathrm{~s}^{-1}
$$

A solid line in Fig. 2 is the best fit result of the data with Eq.(2) and it is found that $C_{0} / h N=2.5 \times 10^{-7}$ and $E_{t}=0.62 \mathrm{eV}$.

In addition, Fig. 2 shows $D_{a}$ by other researchers (i.e., Serra et al. [3], Forcey et al. [2], and Dolinsky et al. [12]). The data for F82H $\left(E_{t}=0.58 \mathrm{eV}\right)$ and BATMAN $\left(E_{t}=0.45 \mathrm{eV}\right)$ [3] are very close to the present data, indicating the same type of trap. The data of MANET II $\left(E_{t}=0.62 \mathrm{eV}\right)[2]$ is separate from these data; however, the trapping energy is nearly the same. Discussions by Serra et al. [3] and Forcey et al. [2] indicate that the trap is likely to be associated with the lath boundaries and with dislocations. This is supported by the fact [12] that the traps in $\mathrm{F} 82 \mathrm{H}$ are annihilated by careful annealing at high temperature.

\subsection{Deuterium depth profiles}


Fig. 3 shows deuterium depth profiles at $376 \mathrm{~K}$ before and after ${ }^{4} \mathrm{He}$ irradiation. Before irradiation, represented as 0 dose in the figure, the deuterium concentration is very low and a small peak attributed to deuterium absorption on surface is present at 0 -depth. Due to a finite resolution of the NRA system, deuterium seems to be present at negative depth. Considering the depth resolution of $0.15 \mu \mathrm{m}$ at full width at half maximum and the probe depth, a region between 0.2 and $1.4 \mu \mathrm{m}$ depth is regarded as bulk hereafter. The deuterium permeation flux $(J)$ at steady state before the irradiation is $4.7 \times 10^{15} \mathrm{~m}^{-2} \mathrm{~s}^{-1}$. In diffusion-limited permeation, the deuterium concentration $C_{s}$ in the solution sites can be estimated by

$$
J=D C_{s} / L
$$

In Fig. $3, C_{s}$ is $2.7 \times 10^{21} \mathrm{~m}^{-3}$ and much lower than the average bulk concentration $C_{b}$ of $3.4 \times 10^{25} \mathrm{~m}^{-3}$. Almost all deuterium atoms are trapped and a few atoms are dissolved in the solution sites. As shown in Fig. 3, when the sample was irradiated by ${ }^{4} \mathrm{He}$ ions, many traps were produced to increase the deuterium concentration, and a peak appeared at $1.0 \mu \mathrm{m}$ depth. As shown in Fig. 4, the traps were also produced by $\mathrm{H}$ irradiation. However, in the ${ }^{4} \mathrm{He}$ irradiation the deuterium concentration is much lower and the peak width in the bulk steel is larger (which will be discussed later).

\subsection{Trapping energy}

To estimate trapping energy, $J$ and $C_{b}$ were observed at several temperatures between 376 and $691 \mathrm{~K}$. Prior to the experiment, $C_{b}$ in a non-irradiated sample was observed in the same temperature range. The average concentration $\left(C_{t}\right)$ of trapped deuterium is the difference between $C_{b}$ in the irradiated and the non-irradiated samples. $C_{s}$ is estimated by Eq. (4) with $J$. The temperature dependence of $C_{t}$ and $C_{s}$ are shown as filled symbols in Fig. 5. $C_{t}$ increases with decreasing temperature until it becomes saturated at low 
temperatures. This is because deuterium cannot escape from the trap at low temperatures since the barrier is too high. Assuming that all the traps are occupied by deuterium at lower temperature, Fig. 5 shows that the trap density $C_{0}$ is estimated to be $1.2 \times 10^{27} \mathrm{~m}^{-3}$. In diffusion-limited permeation, there is a quasi-equilibrium between deuterium in the solution site and the trap, and the equilibrium constant $f$ is expressed by [13]

$$
f=C_{s}\left(C_{0}-C_{t}\right) / h N C_{t}
$$

$f$ is related to the trapping energy $E_{t}$ by $f=\mu \exp \left(-E_{t} / k T\right)$ where $\mu$ is the preexponential factor which represents an entropy difference. All parameters in Eq. (5) are given so $f$ can be determined without any fitting procedures. The data for $f$ clearly lie on a straight line (filled circles in Fig. 6), indicating that one type of trap is dominant.

Filled and open symbols in Figs. 5 and 6 represent the data before and after the sample temperature is heated to $691 \mathrm{~K}$, respectively. It is found that the trap is not annihilated even at $691 \mathrm{~K}$ because $f$ does not deviate under the same $C_{0}$. The reason for a slight decrease in $C_{t}$ after $691 \mathrm{~K}$ is that $C_{t}$ is related to $C_{s}$ and $C_{s}$ decreases, probably due to some changes in surface conditions (e.g., oxidation during the $691 \mathrm{~K}$ heating).

The temperature dependence of $C_{t}$ and $C_{s}$ in the H-irradiated sample is shown by filled symbols in Fig. 7. $C_{0}$ is $2.0 \times 10^{26} \mathrm{~m}^{-3}$ and $f$ is determined as shown in Fig. 6. The data of $f$ agree well with those in the ${ }^{4} \mathrm{He}$ irradiation, indicating the same trap in the ${ }^{4} \mathrm{He}$ irradiation. Values of $\mu$ and $E_{t}$ are 0.25 and $0.66 \mathrm{eV}$, respectively.

\subsection{Trap production}

We assume that the traps are produced by atomic displacement damage during irradiation. Fig. 8 shows the evolution of the trap density $\left(C_{0}\right)$ with displacement. Here, the number of displacements is estimated by the TRIM code [14], assuming that displacement 
energy is $20 \mathrm{eV}$ for all the constituent elements. Results of additional experiments under the same conditions of $0.8-\mathrm{MeV}{ }^{4} \mathrm{He}$ irradiation are also shown in Fig. 8 to confirm reproducibility.

In the ${ }^{4} \mathrm{He}$ irradiation cases, $C_{0}$ increases almost linearly with displacement and is less likely to be saturated. This is probably because an atomic fraction of the trap density is much less than unity, 0.014 at maximum. In case of the $\mathrm{H}$ irradiation, $C_{0}$ also increases with displacement; however, the rate of increase is low. Assuming that the atomic fraction of trap density is proportional to displacement, its proportionality constant, called a trap production rate, is 0.0046 and 0.0014 for the $\mathrm{He}$ and $\mathrm{H}$ irradiation, respectively. These values are much smaller than unity because little defects can survive short-time annealing just after irradiation. Likely, the relatively-large value for He irradiation is due to stabilization of the defects by $\mathrm{He}$ ions [15].

In our previous studies, the trap production rate has been obtained as 0.015 for $\mathrm{Ni}$ [15], around 0.011 for Ta [9], 0.021 for $\mathrm{V}$ [16], and 0.007 for Mo [17]. A value of 0.0046 in the present work is significantly smaller than the values for those above materials. In other words, $\mathrm{F} 82 \mathrm{H}$ is more resistant to producing radiation-induced traps compared to these pure materials.

\subsection{Trap sites}

Fig. 9 shows a depth profile of trapped deuterium in the ${ }^{4} \mathrm{He}$ irradiated sample (i.e., the concentration difference in the profiles before and after irradiation). In addition, Fig. 9 shows the distributions of atomic displacement and ${ }^{4} \mathrm{He}$ ions, as estimated by the TRIM code [14]. The former is quite similar to the profile of trapped deuterium while the latter is not. Clearly, the trap is associated with irradiation-induced defects created in the damage zone.

Although the dominant trap type is the same, some differences are seen in ${ }^{4} \mathrm{He}$ and $\mathrm{H}$ irradiation cases. As shown in Fig. 10, the profile of trapped deuterium in $\mathrm{H}$ irradiation 
differs from the distribution of displacements. Some traps seem to have migrated toward the surface. As indicated previously, the trap is not annihilated at $691 \mathrm{~K}$ in the ${ }^{4} \mathrm{He}$ irradiated sample. However, in the $\mathrm{H}$ irradiated sample, the number of the traps began to decrease around $500 \mathrm{~K}$ and decreased by $97 \%$ for $608 \mathrm{~K}$ and $27 \mathrm{~h}$ annealing, as indicated by an open circle in Fig. 7. The trap production rate for ${ }^{4} \mathrm{He}$ irradiation is about three times larger than for $\mathrm{H}$ irradiation.

The above differences would be attributed to He effects. A main defect in F82H induced by $\mathrm{H}$ irradiation is a dislocation loop and the loop density begins to decrease around $520 \mathrm{~K}$ [18]. Arakawa et al. [19] has shown that main defects in ion-irradiated Fe are interstitial-type dislocation loops, that the loop density in He irradiation is about 4 times larger than that in $\mathrm{H}$ irradiation, and that the distribution of the loop density in $\mathrm{H}$ irradiation is broad. Serra et al. [3] and Forcey et al. [2] have pointed out that a dislocation is likely to be the intrinsic trap in ferritic/martensitic steel. In the present work, the trapping energy of the intrinsic trap $(0.62$ $\mathrm{eV})$ is nearly the same as that of the irradiation-induced trap $(0.66 \mathrm{eV}) . \mu$ represents an entropy difference between the solution site and the trap, and becomes unity for no entropy difference. As the solution site is an interstitial one and $\mu$ is of the order of unity, the trap is considered to be a kind of interstitial-like site [20]. From these discussions, the traps observed in the present work are related to dislocation loops.

Neutron irradiation produces dislocation loops in F82H [21]. In the early stages of fusion reactor operation, tritium retention may not be so significant in $\mathrm{F} 82 \mathrm{H}$ at elevated temperatures due to annihilation of the irradiation-induced trap. However, as operation progresses, ${ }^{3} \mathrm{He}$ contetnt increases by tritium decay and the retention is likely to become higher due to stabilization of the traps by ${ }^{3} \mathrm{He}$.

\section{Conclusion}


Hydrogen trap characteristics in ion-irradiated F82H (e.g., the trapping energy, the production rate, and the annihilation temperature) were determined. Traps were produced by 0.8- $\mathrm{MeV}^{4} \mathrm{He}$ or $0.3-\mathrm{MeV} \mathrm{H}$ ion irradiation. Results show that the traps observed were of one type in each irradiation case and had a trapping energy of $0.66 \mathrm{eV}$. This is nearly the same as the trapping energy for the intrinsic trap $(0.62 \mathrm{eV})$, which was estimated from the apparent diffusion coefficient in the time-lag permeation experiments. Based on discussions about trapping energy and based on the entropy term in the equilibrium constant, and based on the types of defects induced by irradiation, we conclude that the F82H trap is an interstitial-type trap associated with dislocation loops produced by the irradiation.

The trap production rate is 0.0046 and 0.0014 for $\mathrm{He}$ and $\mathrm{H}$ irradiation, respectively. Those values are much lower than the values for $\mathrm{Ni}, \mathrm{Ta}, \mathrm{V}$, and Mo. Traps are annihilated around $600 \mathrm{~K}$ for $\mathrm{H}$ irradiation. However, even at $691 \mathrm{~K}$, traps produced by He irradiation remained. Differences in production rate and the annihilation temperature indicate that $\mathrm{He}$ plays a role to inhibit trap annihilation. In a fusion reactor, trap density would depend on material temperature and ${ }^{3} \mathrm{He}$ content as well as the number of atomic displacements.

\section{Acknowledgement}

This work is supported by a Grant-in-aid for Scientific Research for Priority Area 476, "Tritium Science and Technology for Fusion Reactor." 


\section{References}

[1] K. Shiba, M. Enoeda, S. Jitsukawa, J. Nucl. Mater. 329-333 (2004) 243.

[2] K. S. Forcey, I. Iordanova, M. Yaneva, J. Nucl. Mater. 240 (1997) 118.

[3] E. Serra, A. Perujo, G. Banamati, J. Nucl. Mater. 245 (1997) 108.

[4] I. Takagi, H. Kariyama, K. Shin, K. Higashi, J. Nucl. Mater. 200 (1993) 223.

[5] M. Tamura, H. Hayakawa, M. Tanimura, A. Nishimura, T. Kondo, J. Nucl. Mater. 141143 (1986) 1067.

[6] I. Takagi, K. Kodama, K. Shin, et al., Fusion Technol. 25 (1994) 137.

[7] M. Akiyoshi, H. Sakamoto, R. Haraguchi, K. Moritani, I. Takagi, H. Moriyama, Nucl. Instr. Meth. Phys. Res. B232 (2005) 173.

[8] J. Crank, The Mathematics of Diffusion, second Ed., Clarendon, Oxford, 1975. p44.

[9] I. Takagi, S. Watanabe, S. Nagaoka, K. Higashi, Fusion Technol. 41 (2002) 897.

[10] I. Takagi, K. Yoshida, K. Shin, K. Higashi, Nucl. Instr. Meth. Phys. Res. B84 (1994) 393.

[11] R. A. Oriani, Acta Metall. 18 (1970) 147.

[12] Yu. N. Dolinsky, Yu. N. Zouev, I. A. Lyasota, I. V. Saprykin, V. V. Sagaradze, J. Nucl. Mater. 307-311 (2002) 1484.

[13] I. Takagi, J. Nucl. Sci. Technol. 29 (1992) 947.

[14] J. F. Ziegler, J. P. Biersack, U. Littmark, The Stopping and Range of Ions in Solids, Pergamon, New York, 1985.

[15] I. Takagi, H. Fujita, K .Yoshida, K. Shin, K. Higashi, J. Nucl. Mater. 212-215 (1994) 1411.

[16] I. Takagi, N. Matsubara, M. Akiyoshi, T. Sasaki, K. Moritani, H. Moriyama, J. Nucl. Mater. 363-365 (2007) 955.

[17] I. Takagi, S. Watanabe, S. Nagaoka, K. Higashi, Fusion Tech. 41 (2002) 897.

[18] Y. Dai, X. Jia, S. A. Maloy, J. Nucl. Mater. 343 (2005) 241. 
[19] K. Arakawa, H. Mori, K. Ono, J. Nucl. Mater. 307-311 (2002) 272.

[20] I. Takagi, M. Akiyoshi, N. Matsubara, T. Nishiuchi, K. Moritani, T. Sasaki, H.

Moriyama, J. Nucl. Mater. 367-370 (2007) 489.

[21] E. Wakai, Y. Miwa, N. Hashimoto, et al., J. Nucl. Mater. 307-311 (2002) 203. 


\section{List of Figures}

Fig. 1. Transient permeation flux through F82H sample after the shutter is switched to the large hole (increase) and to the small holes (decrease).

Fig. 2. Apparent diffusion coefficient of deuterium in F82H estimated by the time-lag method. Other experimental works on ferritic/martensitic steel are also shown.

Fig. 3. Deuterium depth profiles in $\mathrm{F} 82 \mathrm{H}$ at $376 \mathrm{~K}$ before and after $0.8-\mathrm{MeV}^{4} \mathrm{He}$ irradiation.

Fig. 4. Deuterium depth profiles in $\mathrm{F} 82 \mathrm{H}$ at $373 \mathrm{~K}$ before and after $0.3-\mathrm{MeV} \mathrm{H}$ irradiation.

Fig. 5. Temperature dependence of the deuterium concentrations in the ${ }^{4} \mathrm{He}$ irradiated sample. Filled and open symbols represent the data before and after heating up to $691 \mathrm{~K}$, respectively.

Fig. 6. Deuterium equilibrium constant between the trap and the solution site in ${ }^{4} \mathrm{He}-$ and $\mathrm{H}$ irradiated $\mathrm{F} 82 \mathrm{H}$.

Fig. 7. Temperature dependence of the deuterium concentrations in the He irradiated sample. An open circle represents the deuterium concentration in the trap after annealing at $608 \mathrm{~K}$ for $27 \mathrm{~h}$.

Fig. 8. Evolutions of the trap density with atomic displacement in ${ }^{4} \mathrm{He}-$ and $\mathrm{H}$-irradiated F82H.

Fig. 9. A depth profile of trapped deuterium in ${ }^{4} \mathrm{He}$-irradiated F82H at $376 \mathrm{~K}$. Distributions of atomic displacement and ${ }^{4} \mathrm{He}$ ion estimated by the TRIM code are also shown in arbitrary unit.

Fig. 10. A depth profile of trapped deuterium in ${ }^{4} \mathrm{He}$-irradiated F82H at $373 \mathrm{~K}$. Distributions of atomic displacement and ${ }^{4} \mathrm{He}$ ion estimated by the TRIM code are also shown in arbitrary unit. 


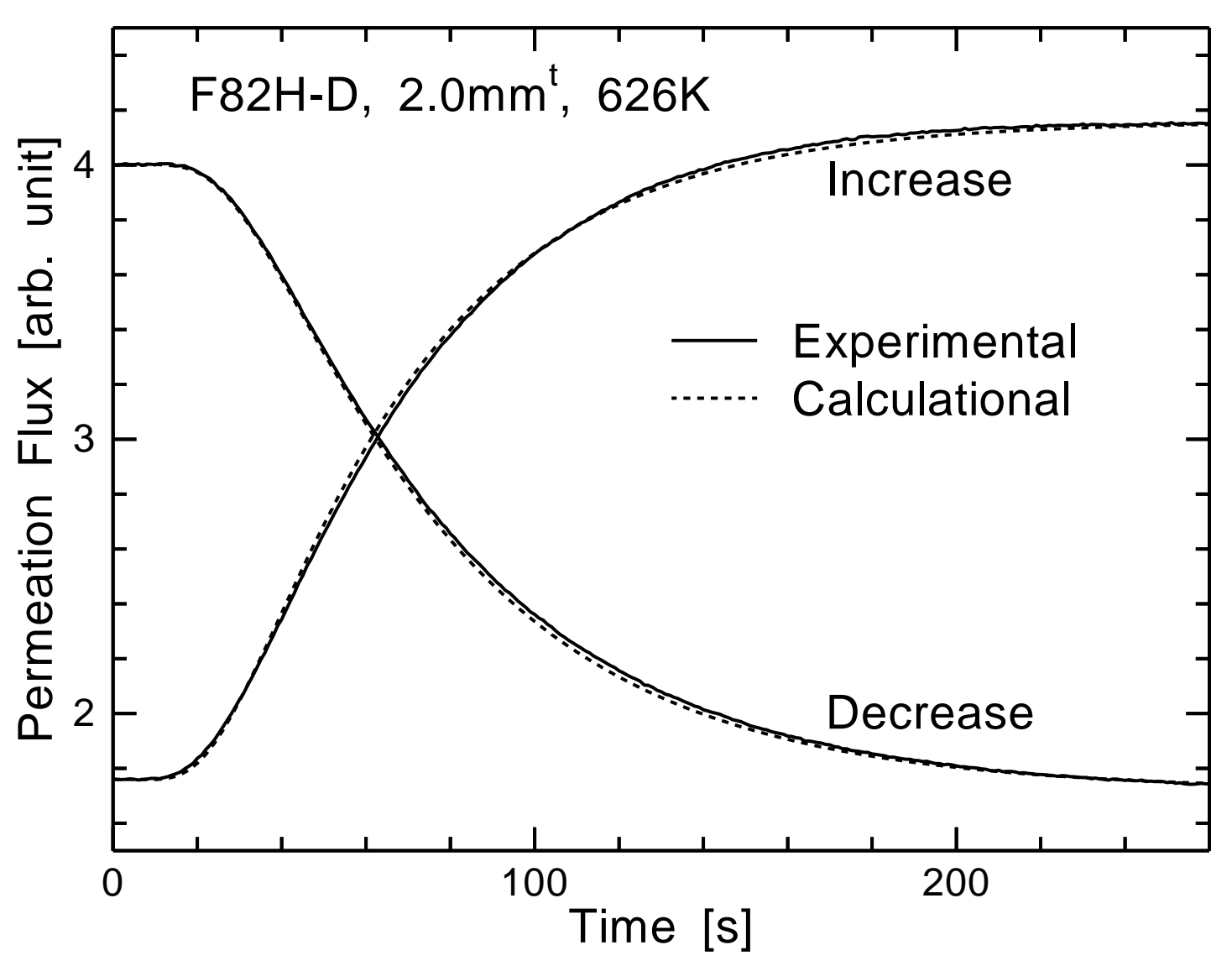

Fig.1 


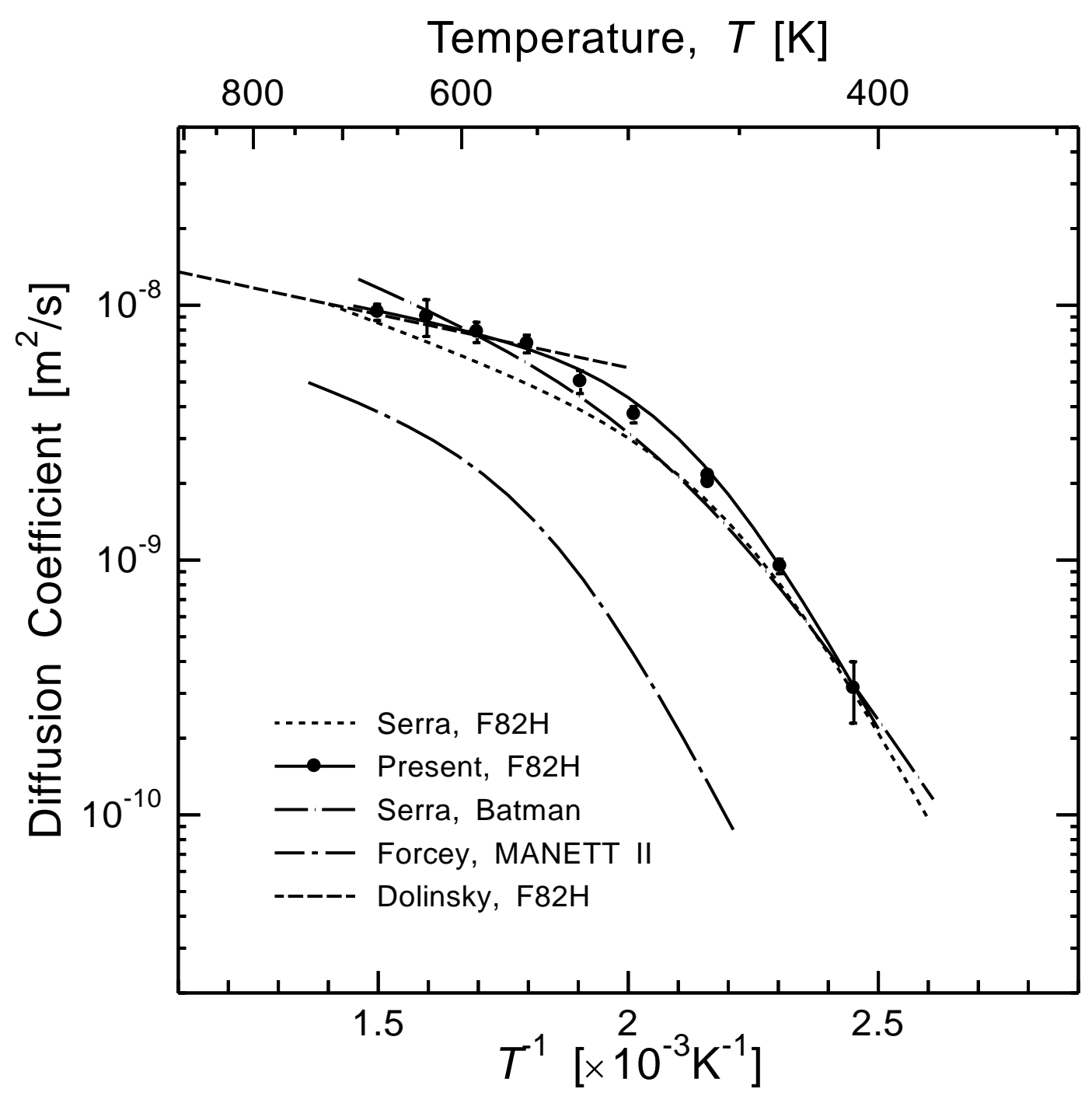

Fig.2 


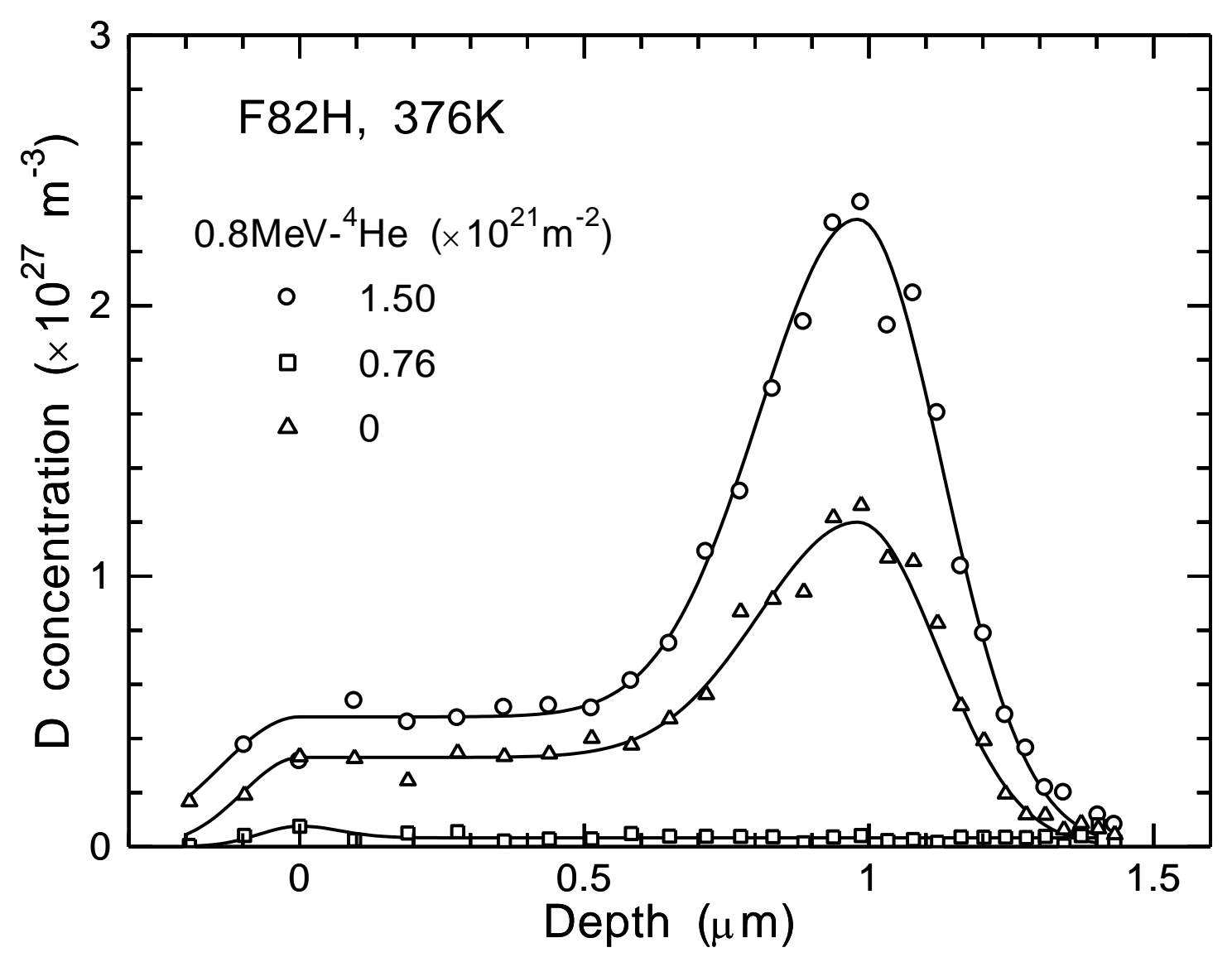

Fig. 3 


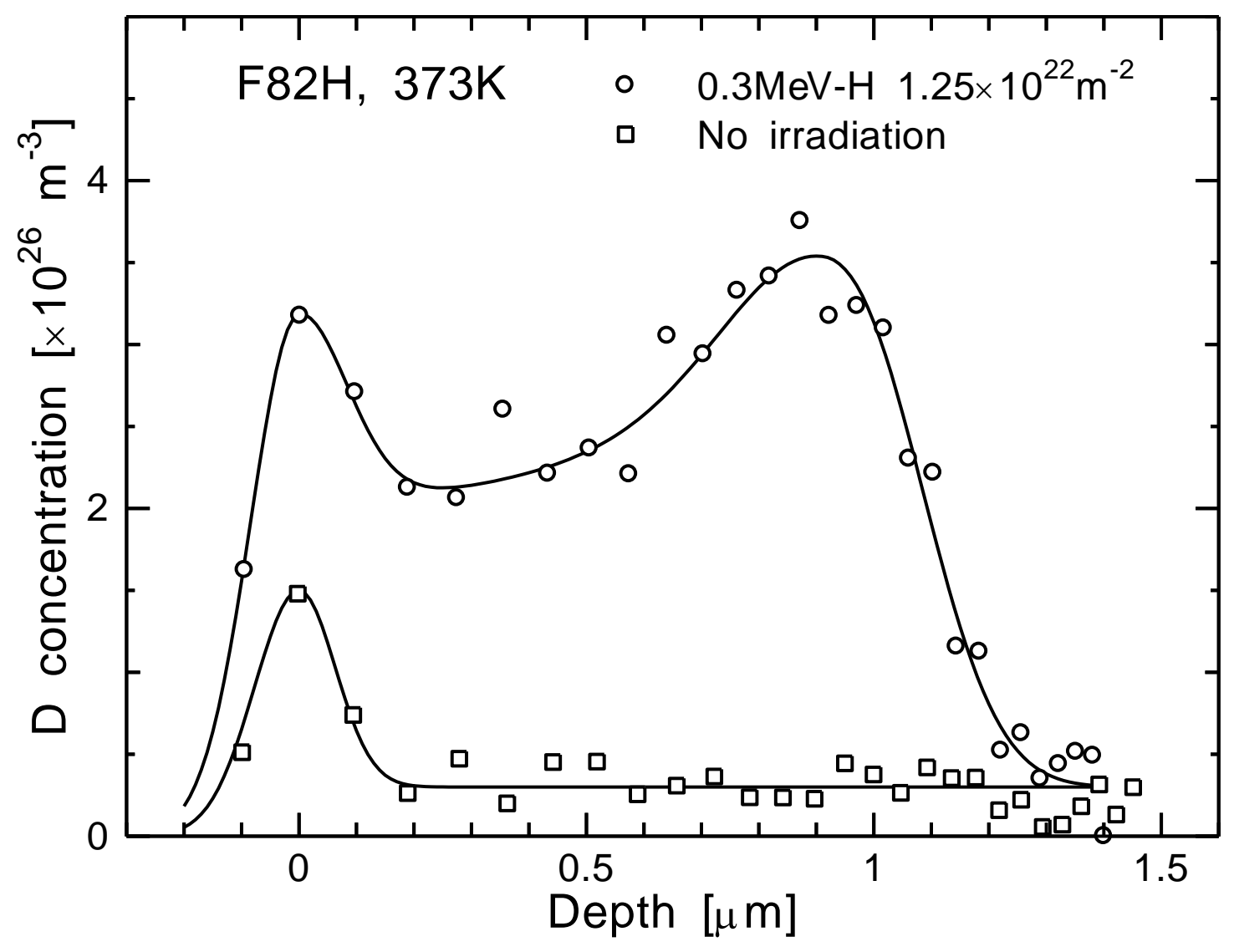

Fig.4 


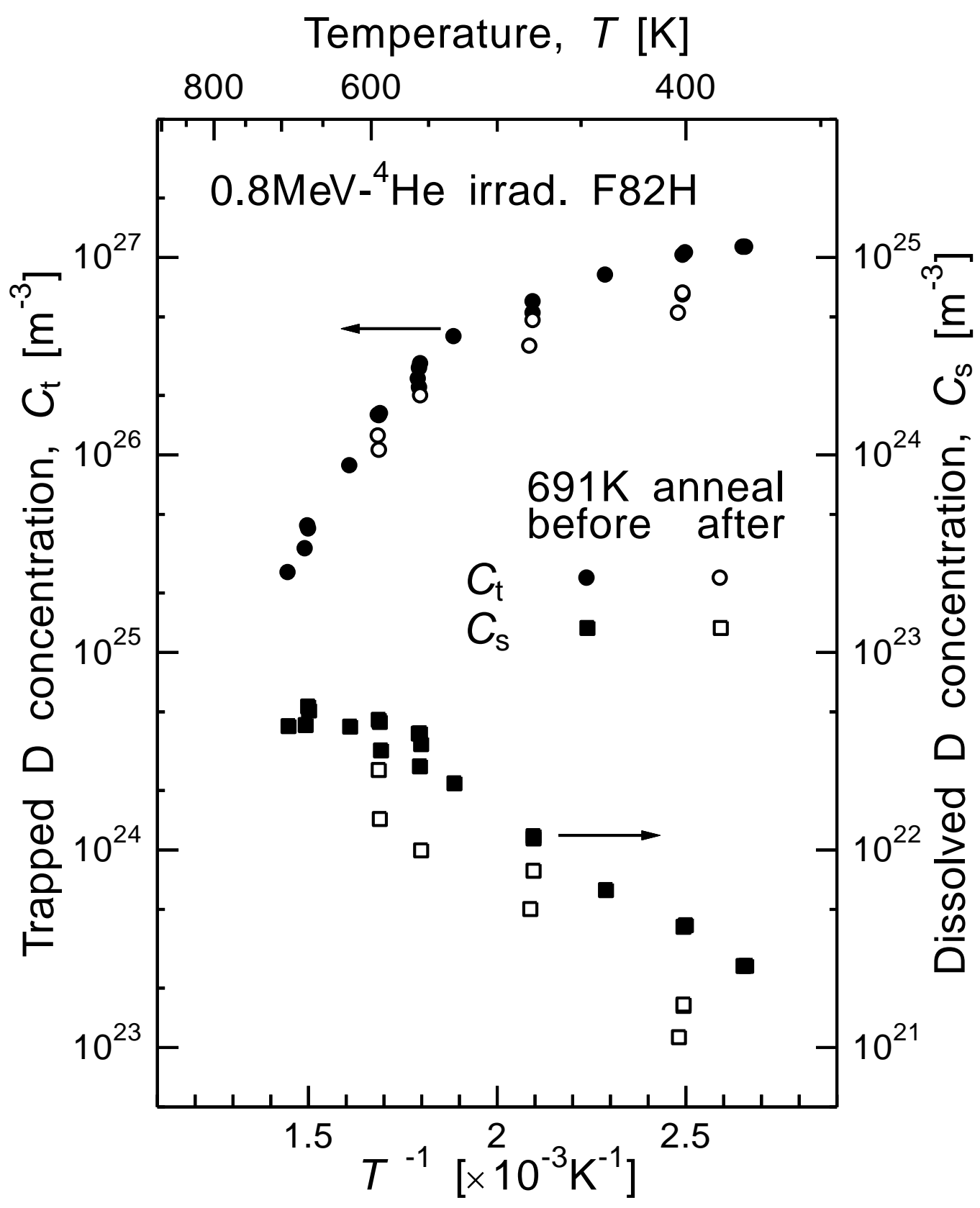

Fig. 5 


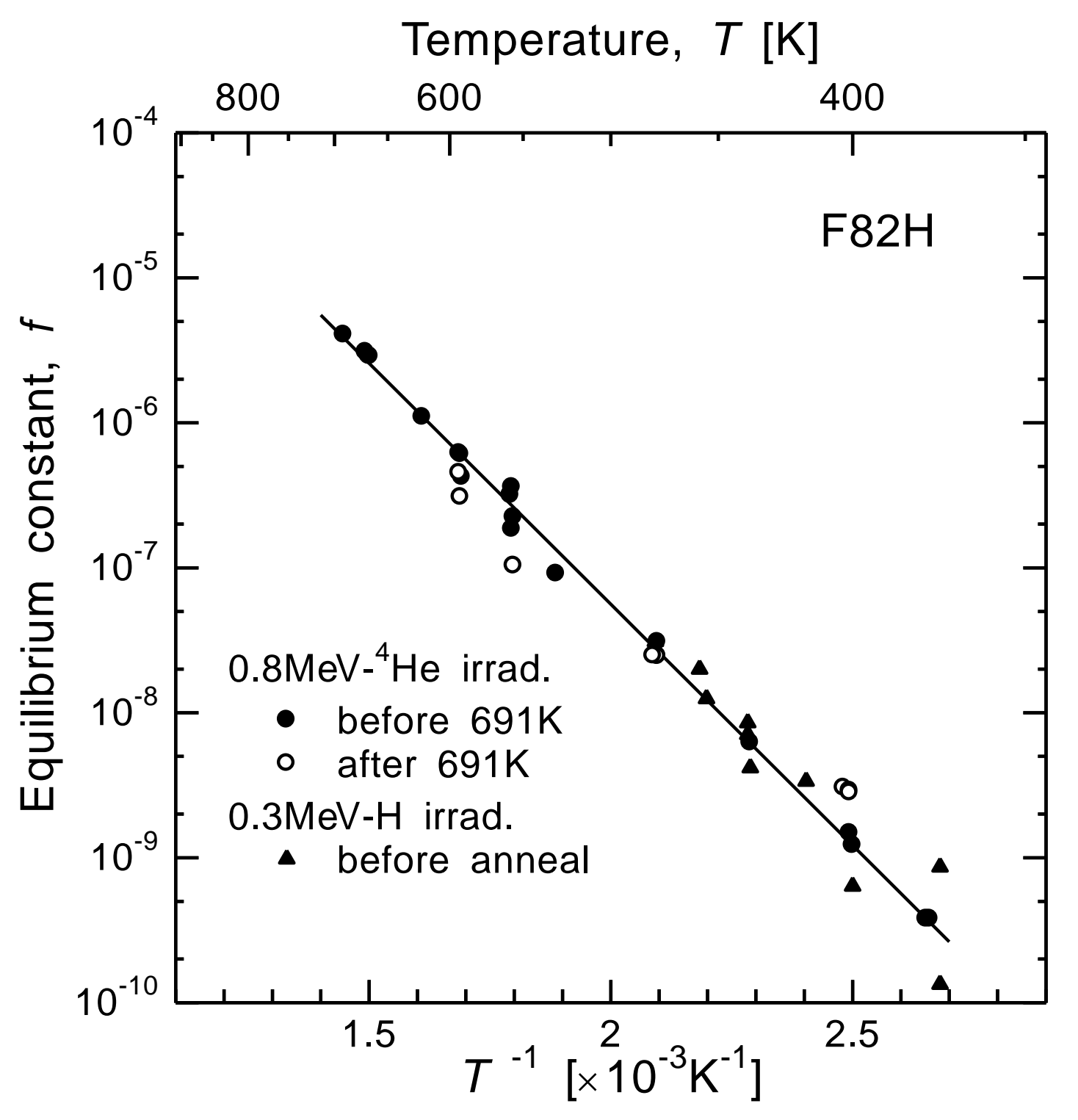

Fig. 6 
Temperature, $T[\mathrm{~K}]$

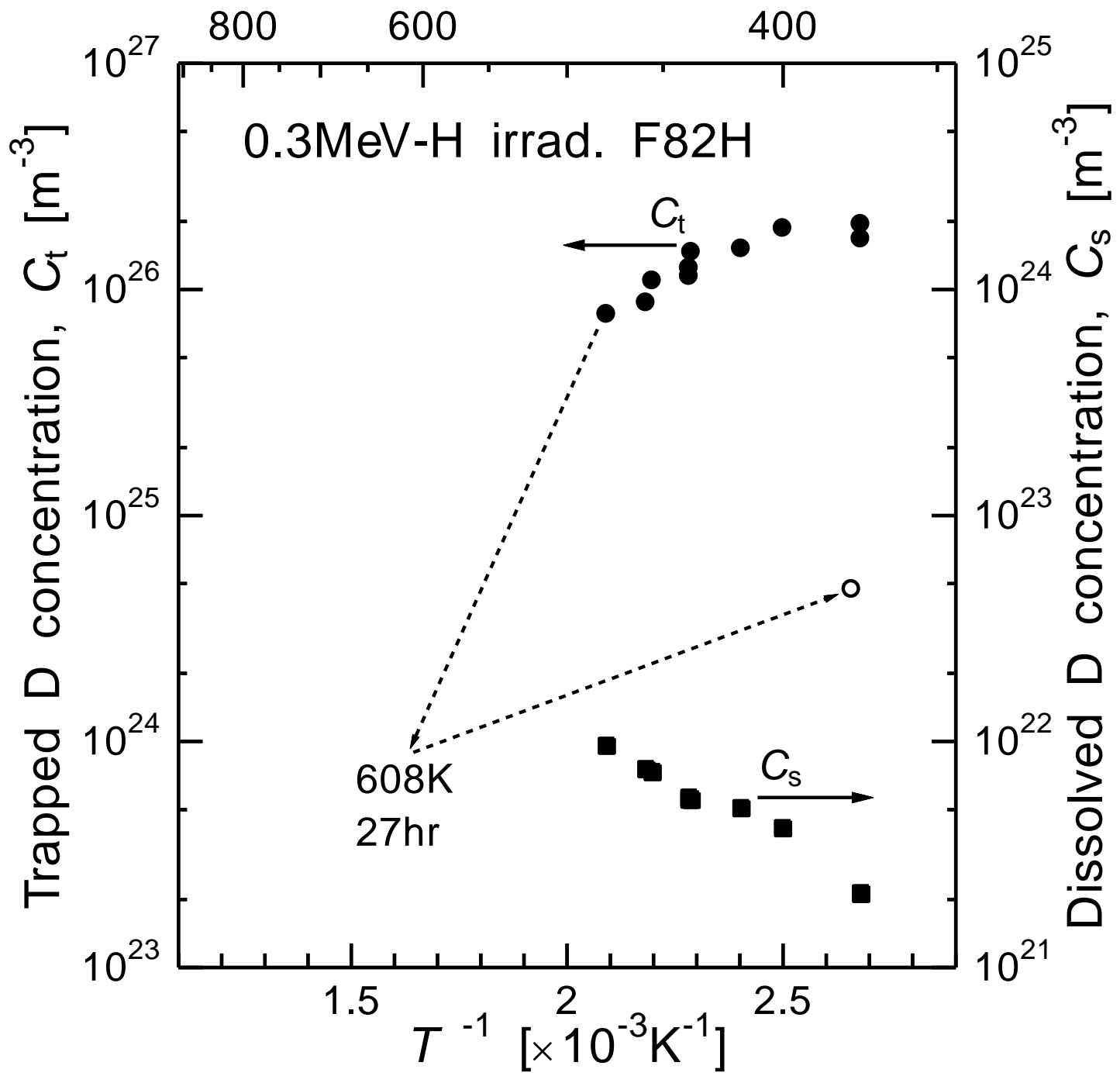

Fig. 7 


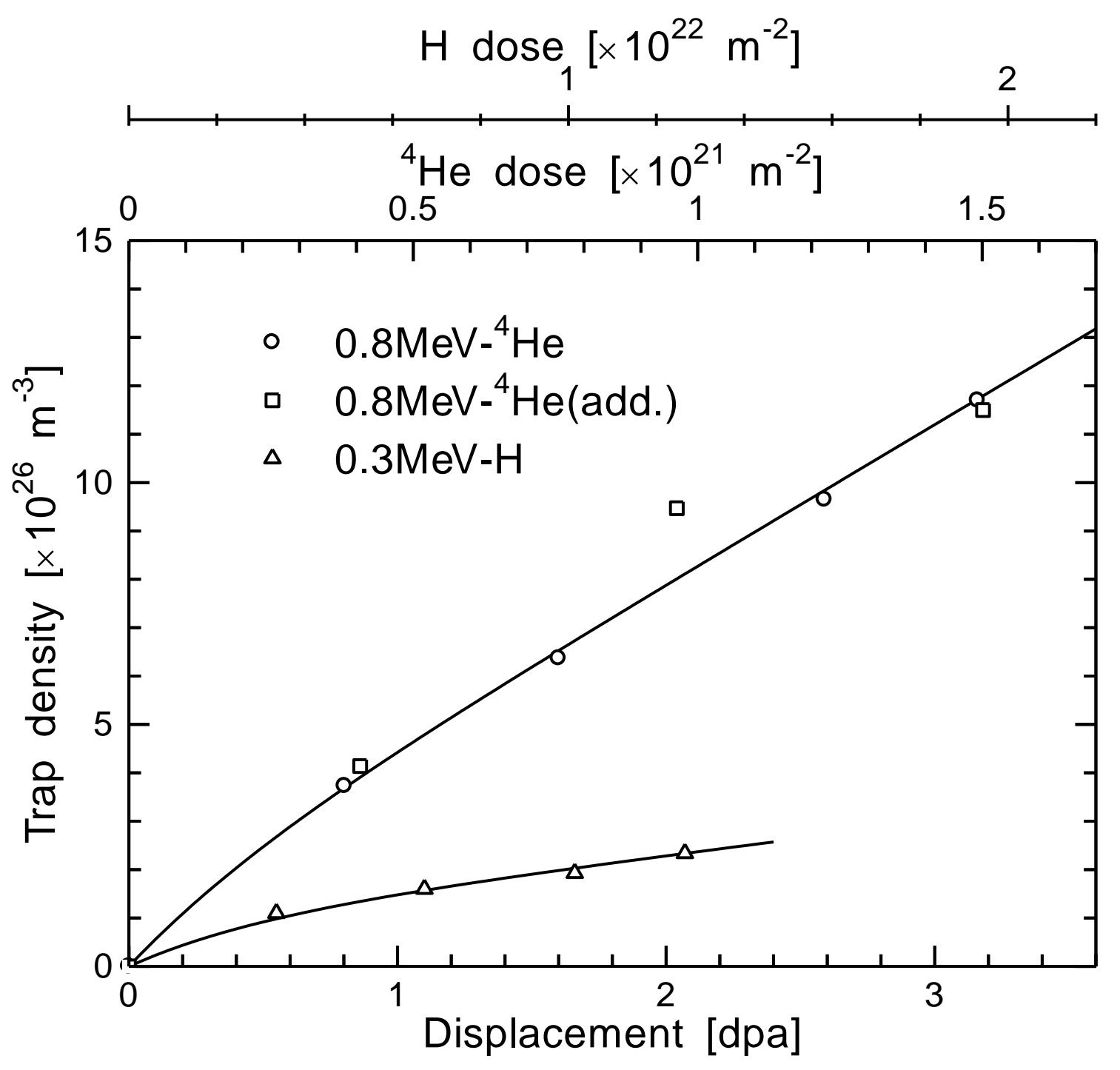

Fig. 8 


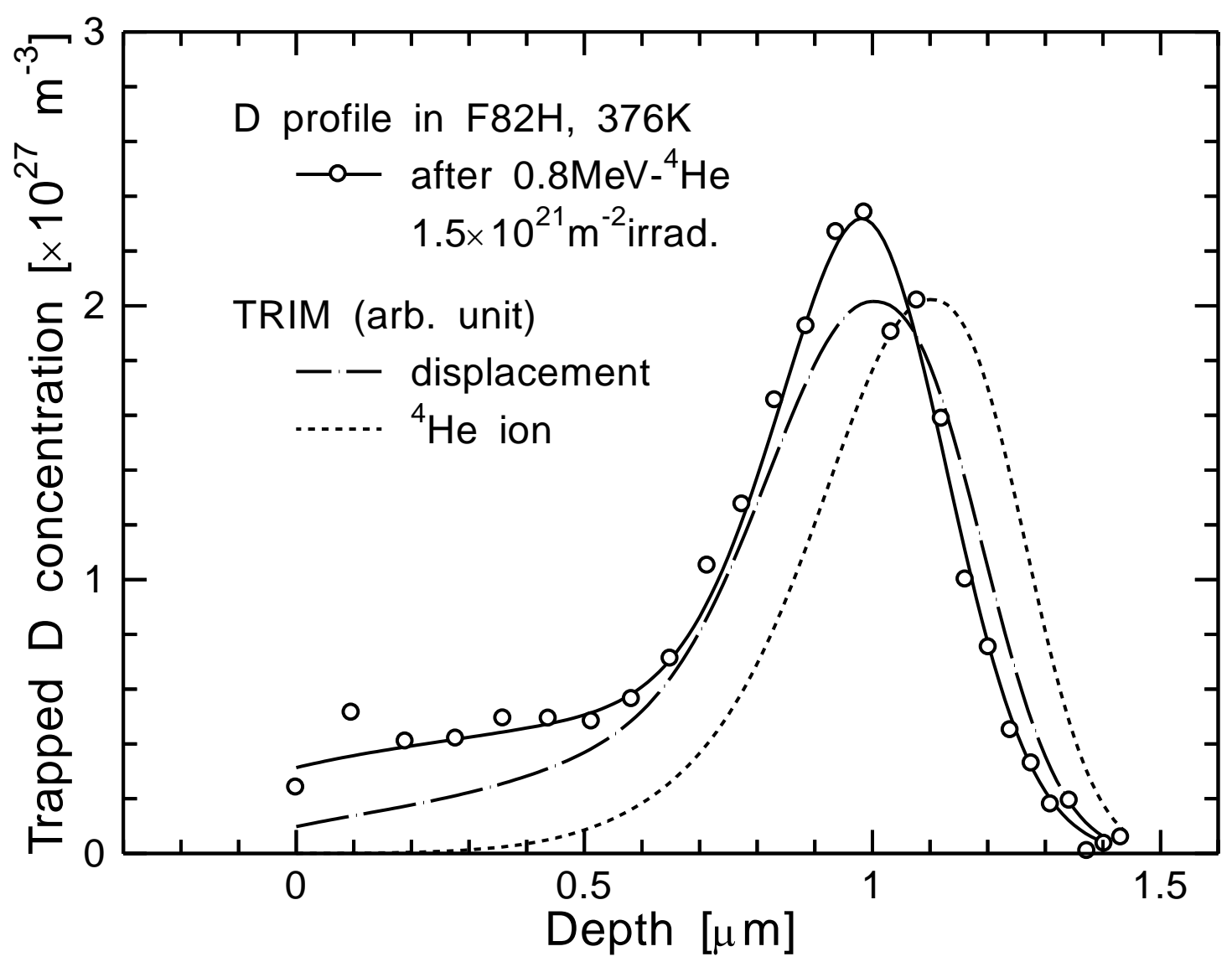

Fig. 9 


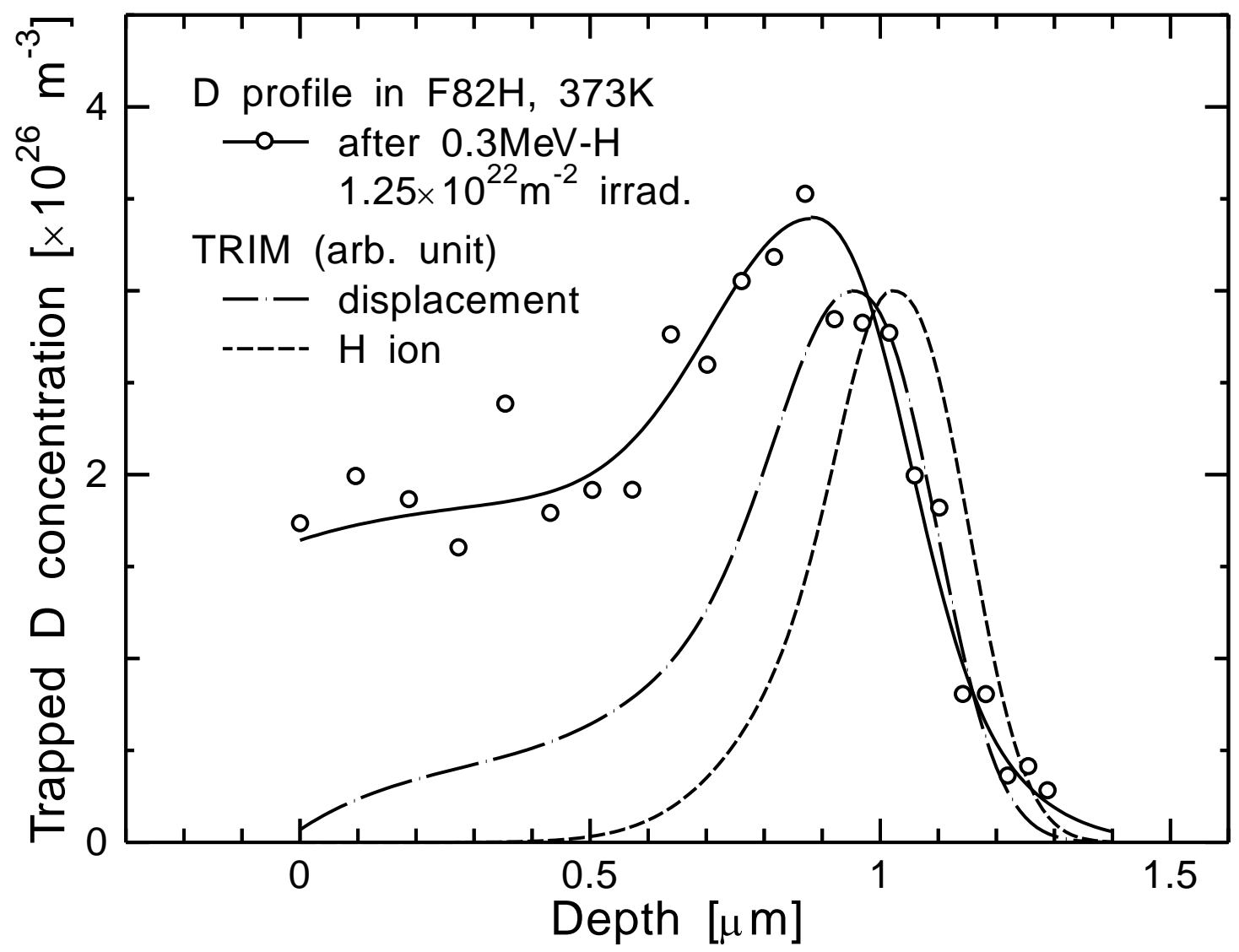

Fig. 10 